Clinical use of moclobemide in Kleine-Levin syndrome

SIR: The Kleine-Levin Syndrome (KLS) is a peculiar disorder that primarily affects adolescent males. First described by Kleine (1925), the syndrome is characterised by alternating episodes of hypersomnia and hyperphagia. Critchley (1962) included disturbances of mood and other appetitive functions as symptoms of KLS. KLS patients present with acute onset of stupor, relative ease of arousal, irritability on awakening, and hyperphagia. There is also withdrawal from social contact.

I report below a patient with KLS who was administered moclobemide as treatment for the disorder.

Case report. A 40-year old male patient had a history of alternating hypersomnia, hyperphagia, sadness, and psychomotor retardation spanning 12 years, without fluctuation and occurring in episodes lasting 15-25 days every 3-4 months. Neuroradiological investigations (skull X-ray, computerised tomography (CT) scan) were inconclusive. Repeated electroencephalogram (EEG) showed nonspecific slow wave activity alternating with bursts of $8-12 \mathrm{~Hz}$ activity, activation of slow-wave activity with eye opening and reduction of sleep spindles. His thyroid function was within normal limits, while the dexamethasone suppression test (DST) was positive during the active phase ( $>15 \mu \mathrm{g} / \mathrm{dl}$ ) and became non-suppressing after recovery.

Over the years, he had received various tricyclic antidepressants, lithium, carbamazepine and 5-HT reuptake inhibitors, with no significant response. Since June 1991, the patient has been receiving moclobemide $(300 \mathrm{mg} / \mathrm{day})$. There has been marked improvement with no relapse of symptoms for 12 months. In addition, no significant sideeffects of the drug have yet been reported.

I am not aware of other reports of moclobemide responsiveness in KLS. As we do not yet have an effective treatment for this rare disorder it is suggested that reversible inhibitors of monoamines may be tried in the treatment of KLS.

Department of Psychiatry

HaROon Rashid Chaudhry

Fatima Jinnah Medical College

Lahore

Pakistan

Critchley, M. (1962) Periodic hypersomnia and megaphagia in adolescent males. Brain, 85, 628-657.

Kleine, W. (1925) Periodische Schlafrucht Msehr Psychiatry: Neurology, 57, 285.

\section{Lay theories of schizophrenia}

SIR: Without wishing to downplay the value of Furnham \& Bower's comparison of academic and lay theories of schizophrenia (Journal, August 1992, 161, 201-210), there are some problems in their interpretation. They have not described here a 'lay theory' but a goodness of fit with professional models. Respondents were provided with a medical term, schizophrenia (which Furnham himself has previously shown carries a rather different lay meaning), together with a professionally derived symptom list and set of attributes; clearly the authors themselves have a category in mind which is independent of any conceptualisation, for they talk of "schizophrenia itself". Out of responses to the attributes offered they then derive their lay model and even its structure.

The questionnaire used was entitled 'beliefs' (and this is presumably a term for the readers of the paper, not just the respondents), and the authors themselves make an initial distinction between attitudes ('subjective feelings') and 'objectively verifiable' beliefs, yet the suggested attributes are in part concerned with the moral status of schizophrenia. Rather than have recourse to the debatable psychological distinction between attitudes and beliefs, it might be more helpful to examine the boundaries and context of the model itself; for instance, is it representational or operational (Holy \& Stuchlik, 1982)? The context and design of the current study argues for generating a model which is itself somewhat operational or even explanatory (Caws, 1974).

A more serious problem is the authors' assumption that the logical structure of lay (or indeed professional) models is one which is to be revealed in factor analysis, and which is thus independent of respondents' own implicit statements (White, 1982). We are not arguing that there is some real model inside people's heads which they or the authors have failed to ascertain, but that lay theories are more logically messy, variable and contextual than is allowed for in this paper. Given the diversity of the professional (and hence somewhat standardised) models they cite, it might be surprising if lay models had any greater coherence. Perhaps not, but if we reverse the procedure and let psychiatrists give responses to lay models, then the local professional responses themselves approximate to local lay models more than they do to each other (Townsend, 1978).

C^ws, P. (1974) Operational, representational and explanatory models. American Anthropologist, 76, 1-10.

Holy, L. \& Stuchlik, M. (1981) The Structure of Folk Models. London: Academic Press.

TOWNSEND, J. M. (1978) Cultural conceptions and Mental Illness: A Comparison of Germany and America. Chicago: Chicago University Press. 
WhITE, G. M. (1982) The ethnographic study of cultural knowledge of 'mental disorder'. In Cultural Conceptions of Mental Health and Therapy (eds A. S. Marsella \& G. M. White). Dordrecht: Reidel.

ROLAND LITTLEWOOD

SUSHRUT JADHAV

University College and Middlesex School of Medicine Department of Psychiatry

Wolfson Building

Middlesex Hospital

Riding House Street

London WIN 8AA

\section{Probing dexfenfluramine}

SIR: The recent article by O'Keane et al (Journal, May 1992, 160, 643-646) on the use of dexfenfluramine was most interesting. However, one wonders how predictable that response to dexfenfluramine is, in terms of its neuroendocrine action? Rowland \& Carlton (1986) have indicated that the plasma halflife of this compound is around 24 hours, with a half-life of about four hours in brain tissue, and one wonders how the neuroendocrine parameters might vary within this time frame?

Our own experiences with this compound have led us to believe that the drug is quite capricious in terms of its effects. Three patients taking dexfenfluramine have recently come to our attention, and their responses have been vastly different. The first, a middle-aged woman, slept solidly for 72 hours after a single dose of dexfenfluramine. She subsequently stopped taking the drug. The second, a young woman, became acutely suicidal following a threeweek course of dexfenfluramine, and the third, a man in his $40 \mathrm{~s}$, presented with agitation and dysphoria following a four-week course of the drug. Both of these patients were euthymic following discontinuation of the compound.

The manufacturers of dexfenfluramine assure us that the preparation is safe and effective, but the recent work by Ricuarte et al (1991) would suggest that the potential for neurotoxicity with dexfenfluramine is greater than previously believed. Our clinical experiences have made us wary of this drug, as we have found it to be quite unpredictable in terms of its affects.

Ricuarte, G. A., Molliver, M. E., Martello, M. B. (1991) Dexfenfluramine neurotoxicity in brains of non-human primates. Lancet, 338, 1487-1488.

RowLAND, N. E. \& CARLTON J. (1986) Neurobiology of an anorectic drug: dexfenfluramine. Progress in Neurobiology, 27, 13-62.

Department of Psychiatry

University of Alberta

Edmonton, Alberta

Canada T6G $2 B 7$

Alan Byrne
FEARGUS O'CROININ TERRY ZIBIN

Alberta Hospital Ponoka

Ponoka, Alberta

Canada TOC $2 \mathrm{HO}$

\section{Carbamazepine and episodic dyscontrol}

SIR: Lewin \& Sumners describe remission of aggression with carbamazepine, in a chronically irritable, brain-damaged man (Journal, August $1992,161,261-262)$, and argue that the lesion may be frontal or temporal. However, they make a diagnosis of episodic dyscontrol (ED), while admitting that their patient falls short of DSM-III-R Intermittent Explosive Disorder, which excludes cases with between-episode aggressiveness.

Although the term episodic dyscontrol is often used loosely, an intermittent or 'out of character' quality of the aggression is central to the syndrome, and patients often express extreme remorse (Malatsky, 1973). This is reminiscent of the co-occurrence of aggression and 'hypermoralism' in temporal lobe epilepsy (TLE; Waxman \& Geschwind, 1975). Indeed, TLE-like symptoms are frequent in ED (e.g. Maletsky, 1973). I have recently treated three young male out-patients, who presented with many years of worsening outbursts of violence on minimal provocation, with amnesia for, but not denial of, the assaults. All reported olfactory hallucinations of burning, and two, déjá vu phenomena. Two had psychotic features. All had long periods of placidity between episodes. Only one had electroencephalogram (EEG) abnormalities. Carbamazepine produced complete remission in all three, followed by relapse after non-compliance.

The anticonvulsant phenytoin was effective in 19 of 22 cases of ED (Maletsky, 1973), so it is no surprise that carbamazepine, with its specific effect on limbic structures, should be effective in ED, particularly in the presence of TLE-like symptoms.

Episodic dyscontrol is best understood as paroxysmal violence, due to epilepsy-like dysfunction of limbic structures in the temporal lobe, which responds well to anticonvulsants.

Maletsky, B. M. (1973) The episodic dyscontrol syndrome. Diseases of the Nervous System, 34, 178-185.

Waxman, S. G. \& GeschWIND, N. (1975) The interictal behaviour syndrome of temporal lobe epilepsy. Archives of General Psychiatry, 32, 1580-1586.

Reaside Clinic

Philip SUgarman

Birmingham

B45 9BE 